La Salle University

La Salle University Digital Commons

HON499 projects

Honors Program

Spring 4-23-2020

\title{
Synthesis and Characterization of Bay-Annulated Indigo Derivatives as Ligands for Photoactive Metal Complexes
}

Jacob Mayer

jake.mayer97@gmail.com

Denise Femia

La Salle University, femia@lasalle.edu

Follow this and additional works at: https://digitalcommons.lasalle.edu/honors_projects

Part of the Organic Chemistry Commons

\section{Recommended Citation}

Mayer, Jacob and Femia, Denise, "Synthesis and Characterization of Bay-Annulated Indigo Derivatives as Ligands for Photoactive Metal Complexes" (2020). HON499 projects. 32.

https://digitalcommons.lasalle.edu/honors_projects/32

This Honors Project is brought to you for free and open access by the Honors Program at La Salle University Digital Commons. It has been accepted for inclusion in HON499 projects by an authorized administrator of La Salle University Digital Commons. For more information, please contact careyc@lasalle.edu. 


\section{Synthesis and Characterization of Bay-Annulated Indigo Derivatives as Ligands for Photoactive Metal Complexes \\ Jacob Mayer, Denise Femia \\ Department of Chemistry and Biochemistry, La Salle University, Philadelphia, PA

\section{Abstract}

New small molecule chromophores zinc-bis-7-phenyl-BAI and zinc-bis-7-thiophenyl-BAI were synthesized. These chromophores are designed to have longer excited state lifetimes compared to indigo. Characterization was performed by analyzing their UV-VIS absorbance spectra. Red-shifting was observed as well which allows an increase in the absorbance of lower energy photons which make up a large portion of the sun's radiation. Due to this the photoactive metal complexes formed can be considered for use in organic photovoltaics.

Introduction

Indigo-based chromophores are of interest for organic photovoltaics due to their light absorption absoption and frentier sybater

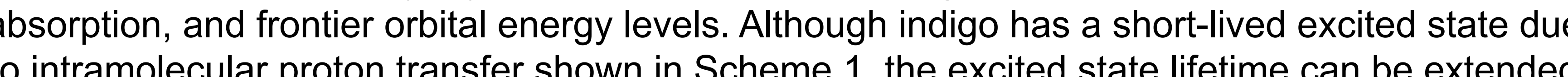
through annulation at the bay position. The benefit of a longer excited state lifetime is that it aids in redirecting the energy that is absorbed. Another effect of this is the shrinking of the up a large portion of the sun's radiation spectrum as shown in Figure 1 .

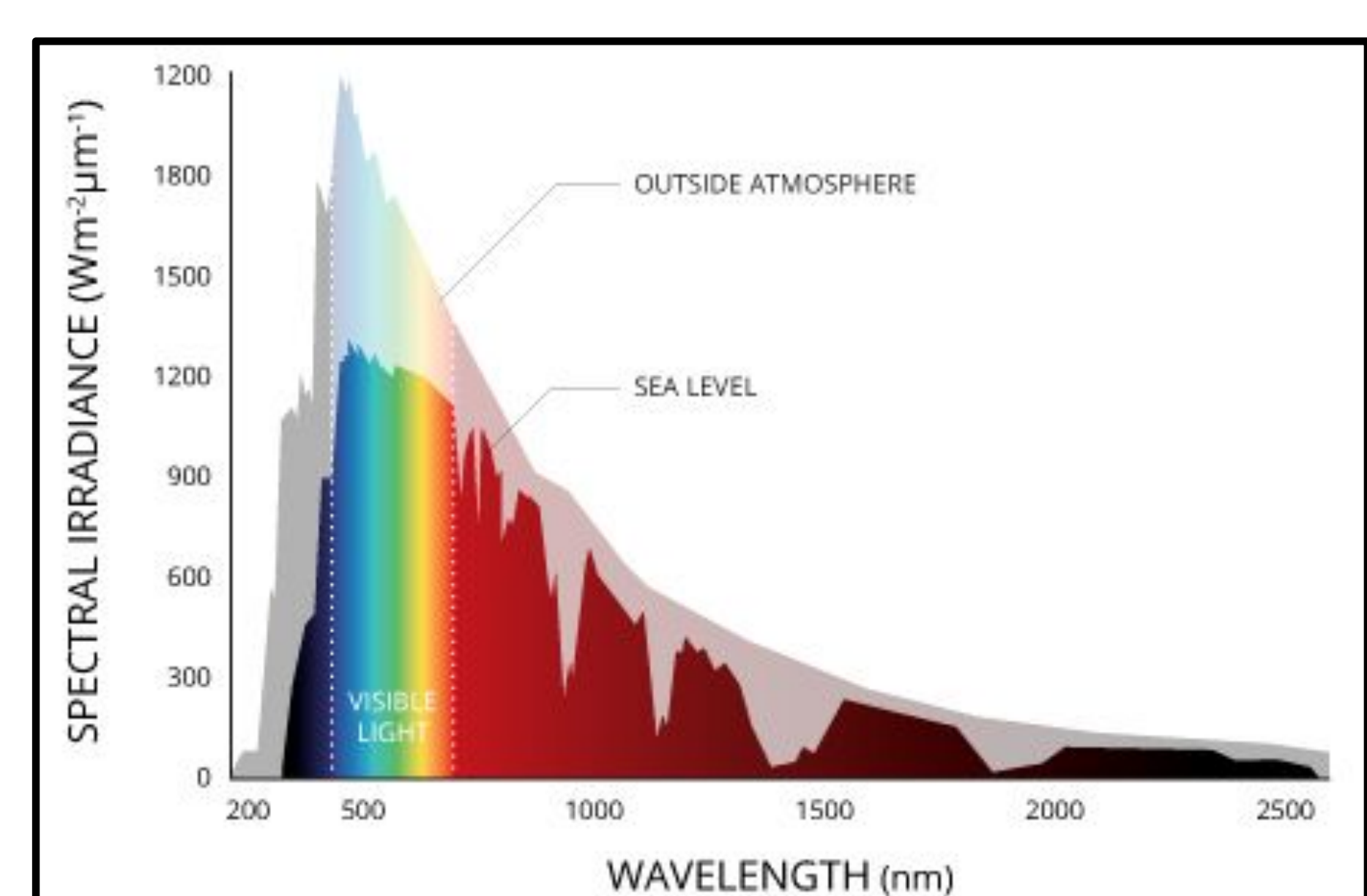
igure 1. Solar radiation spectrum ${ }^{1}$

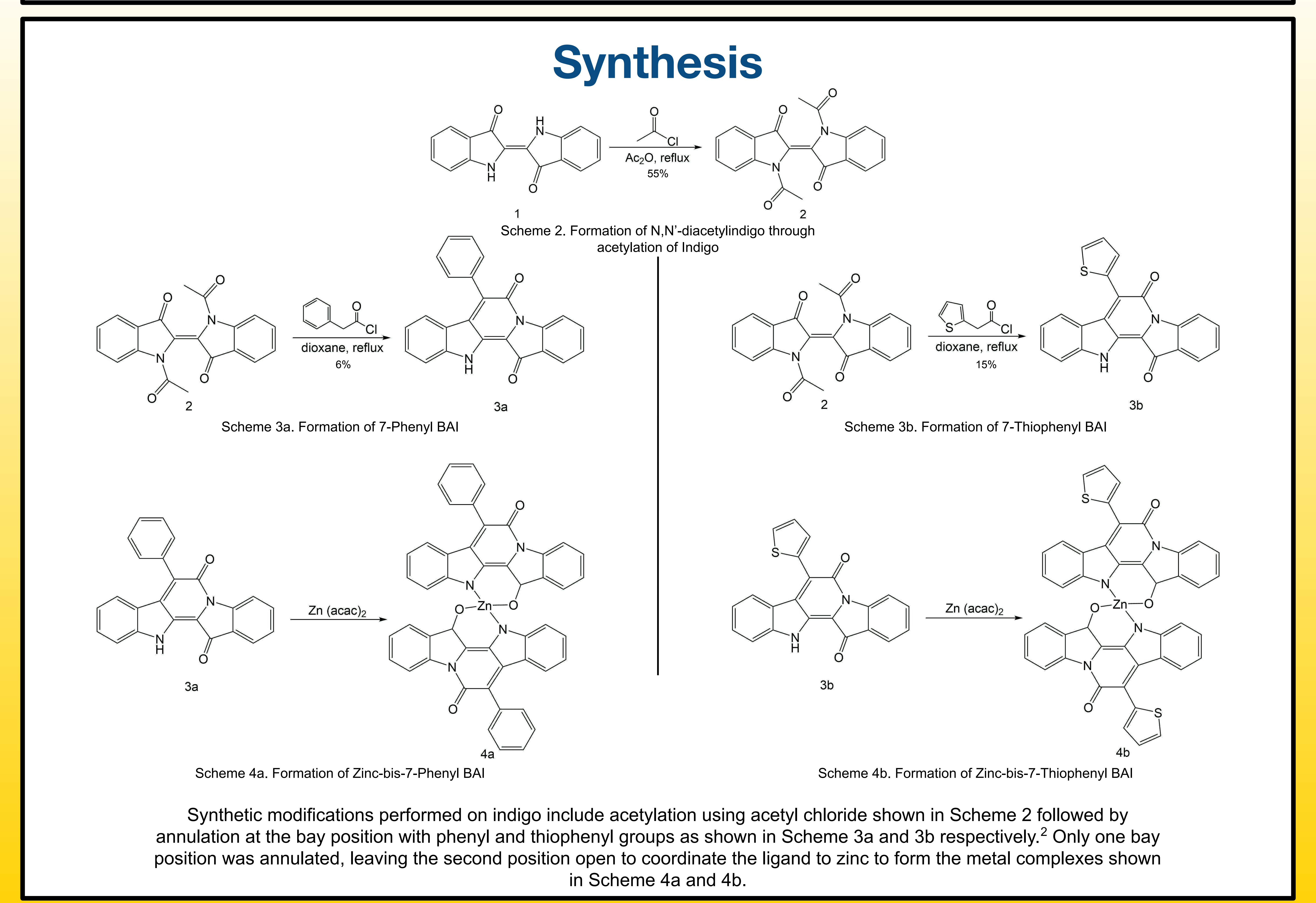

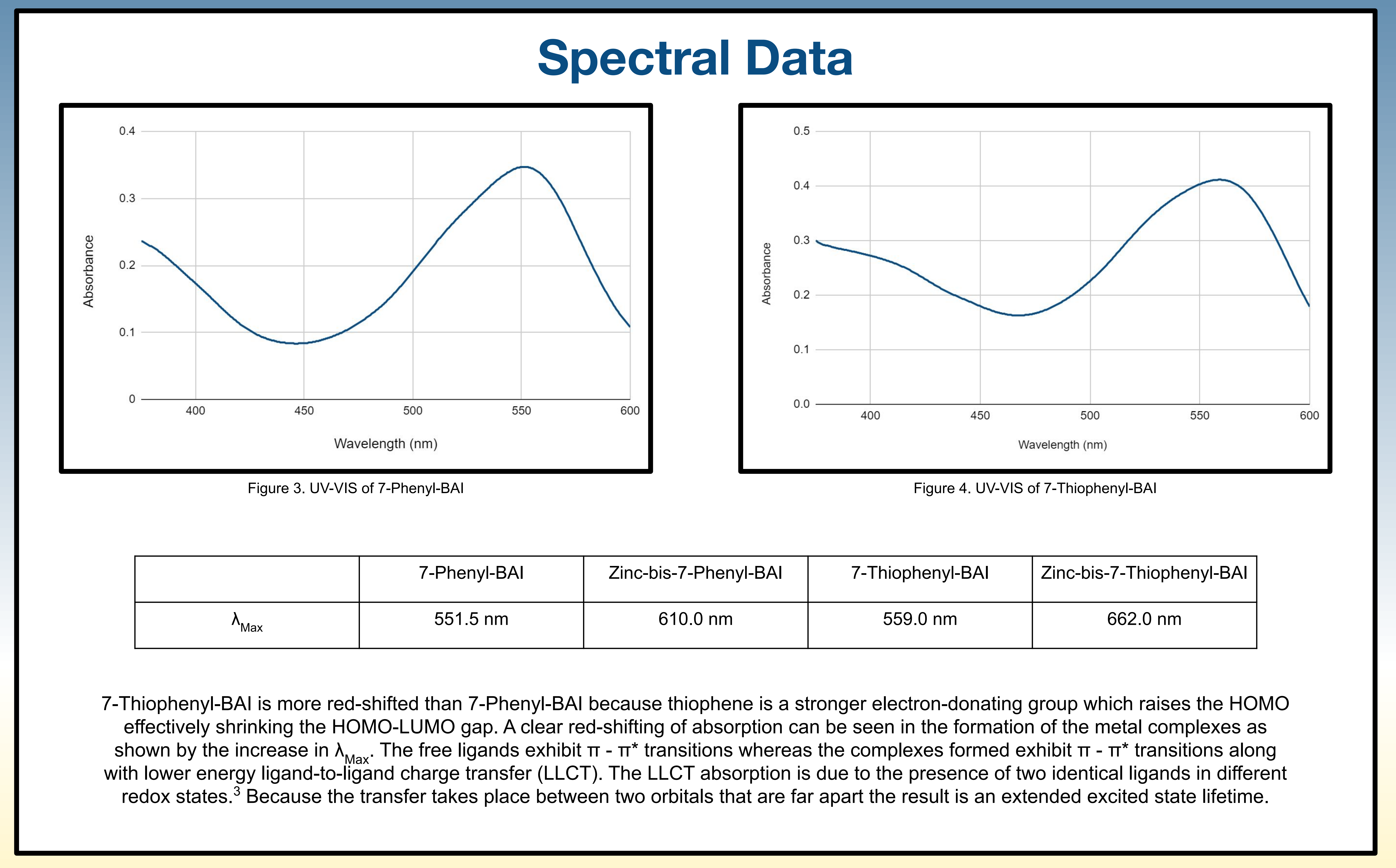

\section{Future Work}

Future research is planned to include further characterization through cyclic voltammetry as well as through molecular modeling to determine the HOMO and LUMO energy and structure of the complexes. In addition new complexes are planned to be synthesized by varying the aromatic group on the bay position of the ligand along with forming complexes with other first row transition metals.

\section{Conclusions}

Zinc-bis-7-phenyl-BAI and zinc-bis-7-thiophenyl-BAI were successfully synthesized from indigo and characterized using UV-VIS. Characterization through UV-VIS was performed by looking at $\pi-\pi^{*}$ transitions and LLCT and comparing $\lambda_{\max }$ to see red shifts. Other forms of characterization are planned for the future to further confirm the synthesis of the products.

\begin{tabular}{|c|}
\hline $\begin{array}{l}\text { Acknowledgements } \\
\text { J.M and D.F were supported by the La Salle University Arts \& Sciences Chemistry } \\
\text { department through the La Salle Arts and Sciences Summer Research Grant }\end{array}$ \\
\hline 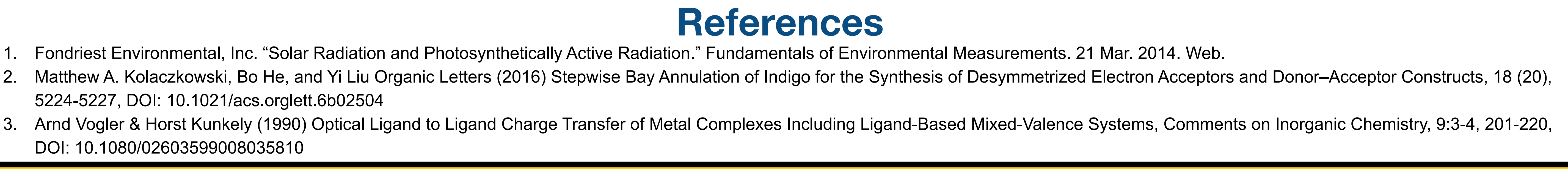 \\
\hline
\end{tabular}

